\title{
Use of real time polymerase chain reaction for detection of M. tuberculosis, M. avium and M. kansasii from clinical specimens
}

Arnold Bainomugisa ${ }^{2,3^{*}}$, Eddie Wampande ${ }^{1,4^{*}}$, Chris Muchwa ${ }^{2,3}$, Joseph Akol ${ }^{2,3}$, Paul Mubiri' ${ }^{3}$, Henry Ssenyungule ${ }^{2,3}$, Enock Matovu ${ }^{4}$, Sam Ogwang ${ }^{2,3}$ and Moses Joloba ${ }^{1,3}$

\begin{abstract}
Background: The incidence of M. tuberculosis (MTB) and non tuberculous Mycobacterium species (NTMs) like M. avium and M. kansasii has increased due to Human Immunodeficiency Virus (HIV) epidemic. Therefore accurate, rapid and cost effective methods for the identification of these NTMs and MTB are greatly needed for appropriate TB management. Thus in this study we evaluated the performance of Lightcycler ${ }^{\circledast}$ Mycobacterium detection assay to detect MTB, M. avium and M. kansasii in sputum specimens.
\end{abstract}

Methods: A total of 241 baseline minimally processed sputum specimens from individual adult TB suspected patients were analyzed by Mycobacterium detection assay (Real-time-PCR) on a LightCycler $480^{\circledR}$ while using liquid culture as a reference standard.

Results: Real time PCR had a sensitivity of 100\% (95\% Cl 96-100) and 100\% (Cl 19-100) for detection of MTB and M. avium respectively. Additionally the assay had a specificity of $99 \%$ (95\% Cl 96-99) and 95\% (95\% Cl 91-97) for identification of MTB and M. avium respectively. The positive predictive value (PPV) for Real time PCR to identify MTB and M. avium among the specimens was $98 \%$ (95\% Cl 94-99) and 15\% (95\% Cl 2-45) respectively. The kappa statistics for Real time PCR to identify MTB and M. avium was 0.9 (95\% Cl 0.9-1.0) and 0.3 (95\% Cl-0.03-0.5) respectively. The median time to detection for Real time PCR assay was 2 hours while overall median time to detection for MGIT-positive cultures was 8 days. The sample unit cost for Real time PCR was $\$ 12$ compared to $\$ 20$ for the reference liquid culture.

Conclusion: The Light cycler ${ }^{\oplus}$ Mycobacterium detection assay rapidly and correctly identified MTB and $M$ avium thus has the potential to be adopted in a clinical setting.

Keywords: M. tuberculosis, M. avium, M. kansasii, Real time PCR

\section{Background}

Mycobacteria species cause a variety of illnesses including pulmonary tuberculosis (PTB) which has profound individual and public health implications [1]. The absolute number of PTB cases occurring each year (9.4 million) is currently greater than at any time in history and the global incidence rate is estimated to have peaked [2]. The continued rise of PTB may be largely attributed to the AIDS pandemic combined with weak healthcare

\footnotetext{
* Correspondence: arnoldbaino@yahoo.co.uk; wampande@covabs.mak.ac.ug ${ }^{2}$ Joint Clinical Research Centre, P.O. Box 10005, Kampala, Lubowa, Uganda 'Department of Medical Microbiology, College of Health sciences, Makerere University, Kampala, Uganda
}

Full list of author information is available at the end of the article delivery systems [3]. Additionally, there is increase in the incidence of non-tuberculosis mycobacterial (NTM) disease in AIDS patients since the first cases in 1982 that complicates the disease [4]. The commonest NTM's associated with pulmonary infection among HIV patients are $M$. avium complex, M. kansasii, M. abscessus and M. fortuitum [5]. The disease caused by M. kansasii often mimics pulmonary tuberculosis in signs and symptoms while $M$. avium causes disseminated disease. The identification of NTMs has lagged behind because of lack of infection awareness among physicians and microbiologists, lack of standardized criteria to define NTM respiratory disease and poor laboratory infrastructure to culture and identify NTMs. The lack of appropriate, 
rapid and accurate diagnostics tools remains critical and undermines progress towards the 2015 millennium development goals for TB control [6]. Therefore, this calls for the need for evaluating more tools to use in accurate diagnosis of TB.

A number of tools have been used in TB diagnosis, for instance smear microscopy the most widely used test has low sensitivity especially in patients with extra pulmonary tuberculosis, those with HIV co-infection and TB due to NTMs [7]. Nucleic acid amplification tests such as PCR based assay have great promise for TB diagnosis and rapid detection of drug resistance with commercial assays widely used in developed countries for over 20 years [8]. However despite their simplicity, they are prone to PCR inhibitors, some tests require post amplification procedures that increases the turn-around time and some are limited by the DNA quantities in the starting material $[9,10]$. Furthermore, since most of these techniques require the isolates to be cultured first, this will introduce growth competition in cases of mixed infection and hence a selection bias. Recently WHO endorsed GeneXpert MTB/RIF for use in the diagnosis of TB in endemic countries [11] but it lacks markers for identification of $M$. avium and $M$. kansasii that are mainly associated with HIV patients. Therefore, the need for an alternative method that can comprehensively detect M. tuberculosis (MTB) and NTMs present in clinical specimens.

In this study we evaluated the LightCycler ${ }^{\circ}$ Mycobacterium detection assay based on the principle of Real-time PCR technology for the detection of $M$. tuberculosis, $M$. avium and $M$. kansasii using species specific hybridization probes designed based on the $16 \mathrm{~S}$ ribosomal RNA (rRNA) gene including the hyper variable region A $[12,13]$. We performed a clinical evaluation on this assay to estimate the cost effectiveness, turnaround time and analytical performance for TB diagnostic potential.

\section{Methods}

\section{Clinical specimens}

A total of 241 baseline sputum specimens collected as part of a standard patient care were randomly selected from clinical specimens sent to our TB laboratory between October 2012-February 2013.

\section{Ethics}

The study protocol was reviewed and approved by the Institutional Review Board (IRB) at Joint Clinical Research Centre (JCRC). Individual informed consent was not sought because the study was conducted on routine samples only and it did not involve any intervention, additional samples or change in patient management. A patient consent waiver was approved by the IRB of JCRC.

\section{Processing of sputum specimens}

All specimens were decontaminated according to the available laboratory protocol [14]. In brief, specimens were 1:1 mixed with $\mathrm{N}$-acetyl-L-cysteine (NALC)- $\mathrm{NaOH}$ (final concentrations 1.5\% NaOH, 0.7\% NaCitrate, 0.25\% $\mathrm{N}$-acetyl-cysteine) and put on plat form shaker (Thermo scientific Inc. USA) at $60 \mathrm{rpm}$ for $20 \mathrm{~min}$. After neutralization with $0.5 \mathrm{M}$ phosphate buffer ( $\mathrm{pH}$ 6.8) and centrifugation $(3000 \times \mathrm{g}$ for $20 \mathrm{~min})$ in order to concentrate the mycobacteria, the sediment was re-suspended with $2 \mathrm{ml}$ phosphate buffer.

Of the sediment, $500 \mu \mathrm{l}$ were inoculated into Mycobacteria Growth Indicator Tubes (MGIT ${ }^{\mathrm{TM}}$ ) (BectonDickenson, Heidelberg, Germany) already supplemented with $800 \mu \mathrm{l}$ final concentration of $12.5 \mathrm{U} / \mathrm{ml}$ polymyxin B, $1.25 \mathrm{mg} / \mathrm{ml}$ amphotericin B, $5 \mathrm{mg} / \mathrm{ml}$ nalidixic acid, $1.25 \mathrm{mg} / \mathrm{ml}$ trimethoprim and $1.25 \mathrm{mg} / \mathrm{ml}$ azlocillin (PANTA) and incubated in the Bactec ${ }^{\text {tw }}$ MGIT 960 system (Becton, Dickinson and Company, Franklin Lakes, $\mathrm{NJ})$ according to the manual of the manufacturer. The leftover suspension $(500$ to $1000 \mu \mathrm{l})$ was kept at $2-8^{\circ} \mathrm{C}$ until further processing in the frame of the present study. The tubes were automatically and continuously monitored for growth and remained in the instrument until it signaled positive for growth or negative at the end of the 42-day incubation. All liquid cultures that turned positive, were screened for acid fastness using Ziehl Neelsen microscopy, inoculated on blood agar plates to detect contaminants and then M. tubeculosis confirmed using MPB64-protein based immunochromatographic assay (capilia TB, TAUNS, Japan) following manufacturers' guidelines. All the Mycobacteria other than tuberculosis (MOTTs) cultures were screened to confirm the presence of $M$. avium and M. kansasii using DNA line probe assay (GenoType Mycobacterium CM, Hain Lifesciences, Nehren, Germany) (see Figure 1).

\section{Isolation of genomic DNA}

In brief, $500 \mu \mathrm{l}$ of the decontaminated sputum sample was spun and pellet re-suspended in $20 \mu \mathrm{l}$ of nuclease free water; heat killed in a heat block set $95^{\circ} \mathrm{C}$ for 1 hour to lyse the bacteria and later sonicated at $37 \mathrm{kHz}$ (Elma S30, Gottlieb-Daimler-Str. Singen, Germany) for 15 minutes. The resultant genomic DNA in the supernatant was recovered by centrifugation at $8000 \mathrm{~g}$ for $3 \mathrm{~min}$ for eventual use in the Real time PCR assay.

\section{Quality control}

Reagents were aliquoted and each aliquot was used only once. Sterile microfuge tubes and 96 PCR well plates for Real time PCR assay use. Reagent preparation, DNA extraction, DNA amplification and detection were performed in separate rooms to avoid cross contamination of amplicons. 


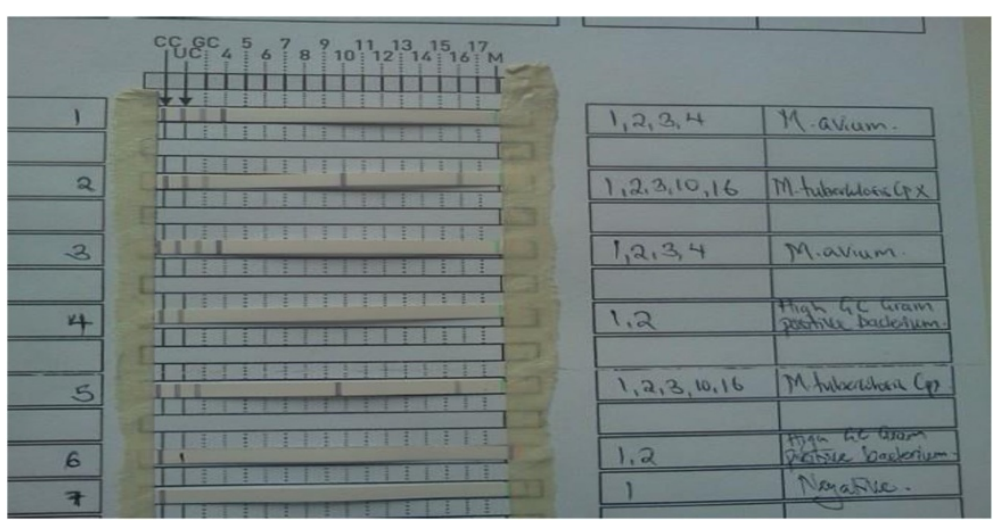

Figure 1 GenoType Mycobacterium CM line probe assay results used to differentiate M. avium and M. kansasii from Mycobacteria other than Tuberculosis (MOTTs).

A positive control (Mycobacterium tuberculosis H37Rv, $M$. avium and $M$. kansasii) was included in each test and distilled water was included as a negative test control. Uracil-N-glycosylase (UNG) was used in the amplification process to avoid post PCR DNA contamination.

\section{Mycobacterium real time PCR}

Real time PCR was performed on a LightCycler 480 II (Roche diagnostics, Mannheim, Germany) according to the manufacturer's instructions using light cycler mycobacterium detection assay. This assay comprised of two major steps: (i) Amplification of internal control sequences and genomic target sequences (ii) melting curve detection by florescence measurement at $640 \mathrm{~nm}$. A $20 \mu \mathrm{l}$ reaction mixture contained $4 \mu \mathrm{l}$ of sample lysate (or $4 \mu \mathrm{l}$ of positive/negative control), $11 \mu \mathrm{l}$ detection mix (primers and probes), $4 \mu \mathrm{l}$ of PCR master mix (Taq polymerase, DNTPs, $\mathrm{Mg}^{2+}$ ), $0.75 \mu \mathrm{l}$ internal control and $0.25 \mu \mathrm{l}$ uracil-DNA gylcosylase. Thermal cycling was as follows: $10 \mathrm{~min}$ at $95^{\circ} \mathrm{C}$, then 45 cycles of $10 \sec 95^{\circ} \mathrm{C}$, $10 \mathrm{sec} 50^{\circ} \mathrm{C}$ and final extension of $20 \mathrm{sec}$ at $72^{\circ} \mathrm{C}$. Melting curve detection to determine the melting temperature
$(\mathrm{Tm})$ values for the target sequences was set as follows: $1 \mathrm{~min}$ at $95^{\circ} \mathrm{C}, 2 \mathrm{~min}$ at $40^{\circ} \mathrm{C}, 75^{\circ} \mathrm{C}$ continuous and then cooling at $10 \mathrm{sec}$ at $40^{\circ} \mathrm{C}$.

\section{Detection}

The LightCycler 480 II analyzed the samples in 2 steps: (i) PCR amplification of the target region where the target amplicon for each sample were detected between the annealing and elongation as sigmoid curves at $640 \mathrm{~nm}$ (see Figure 2) (ii) $\mathrm{Tm}$ calling using the LightCycler $480^{\circ}$ software to determine the melting temperature ( $\mathrm{Tm}$ ) specific for each subtype in the samples (see Figure 3). Range Tm included according to the manufacturer instructions include; 54.4 to $57.4^{\circ} \mathrm{C}$ for $M$. tuberculosis, 47.5 to $50.5^{\circ} \mathrm{C}$ for $M$. avium and 57.5 to $60.5^{\circ} \mathrm{C}$ for $M$, kansasii.

\section{Analysis of data}

The time that elapsed from MGIT sample inoculation and incubation to MGIT culture positivity or negativity was registered as the turnaround time (TAT) for liquid culture. The time difference between the start and stop time for each real time PCR run was used as the

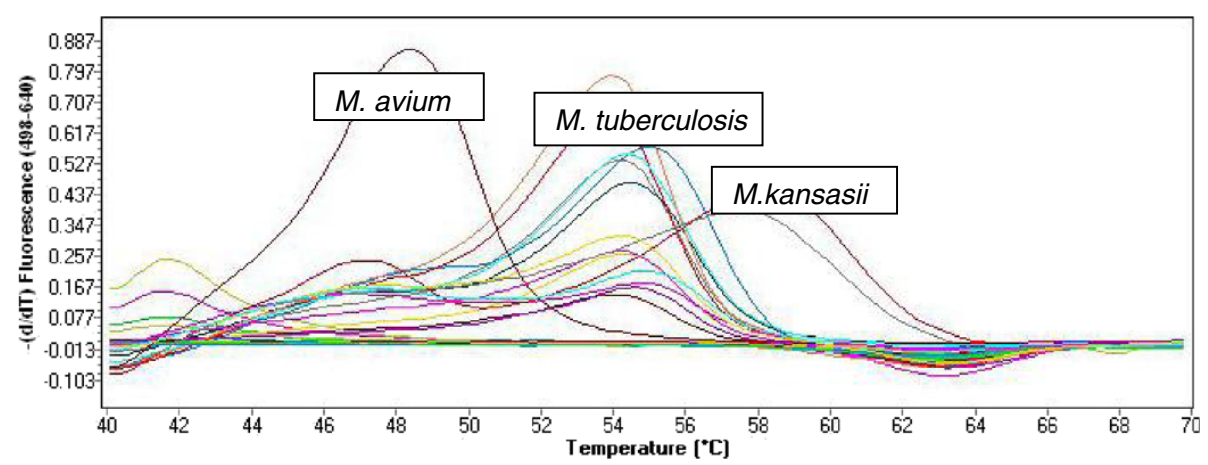

Figure 2 Sigmoid amplification curves captured during anealing and elongation step by the Roche LightCycler 480 II indicating the detection of M. tuberculosis, M. avium or M. kansasii. 


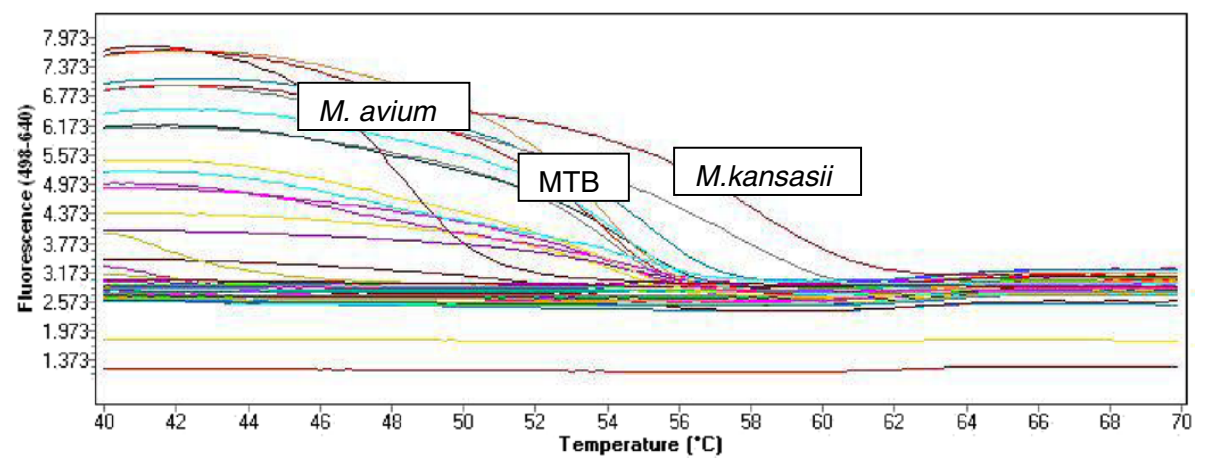

Figure 3 Melting temperature determination using Tm calling on LightCycler $480^{\circledR}$ software determining the different mycobacteria species using temperature ranges; $54.4^{\circ} \mathrm{C}$ to $57.4^{\circ} \mathrm{C}$ for M. tuberculosis, $47.5^{\circ} \mathrm{C}$ to $50.5^{\circ} \mathrm{C}$ for M. avium and $57.5^{\circ} \mathrm{C}$ to $60.5^{\circ} \mathrm{C}$ for M. kansasii.

turnaround time for Real time PCR assay. The unit sample cost between Real time PCR and liquid culture use was achieved by comparing the requirements and their costs to test 241 clinical specimens for identification of M. tuberculosis, M. avium and M. kansasii.

Statistical data were entered and analyzed using $\mathrm{Epi}^{\mathrm{mit}}$ StatCal info version 7 software (CDC, Atlanta). The values got were validated using statistical diagnostic software MedCalc version 15.2.2 (MedCalc Software bvba, Belgium).

\section{Results}

Of the 241 patient sputum specimens (baseline), Real time PCR identified 95 (39\%) specimens as MTB, 13 (5\%) as M. avium and $1 M$. kansasii (0.4\%) while 132 (55\%) were negative. For liquid culture that was used as the reference standard, Capilia-neo TB (TAUNS) confirmed 94 (39\%) MTB, $2(0.8 \%)$ as M. avium and 14 (6\%) were other Mycobacteria other than M. avium and M. kansasii; all confirmed by genotype Mycobacterium HAIN CM. 131 (54\%) specimens were negative (no growth) by liquid culture after 42 days of culture. (see Table 1)

From 2X2 performance analysis (see Table 2), 96 (40\%) sputum samples were identified with mycobacterial species; of these $94(98 \%)$ as MTB and $2(2 \%)$ as M. avium by both methods. The remaining $145(60 \%)$ specimens were not identified as MTB, M. avium or M. kansasii (true negative) by both assays.

\section{Performance of Mycobacterium detection assay}

When using baseline clinical specimens; the sensitivity and specificity of Real time PCR in identifying MTB was 100\% (CI; 96-100) and 99\% (CI; 96-99) respectively while for identification of $M$. avium; sensitivity and specificity was 100\% (CI; 19-100) and 95\% (CI; 91-97) respectively (see Table 3 ). The positive predictive value (PPV) and negative predictive value (NPV) for Real time PCR to identify MTB at was $98 \%$ (CI; 94-99) and 100\% (CI; 97-100) respectively. Identification of $M$. avium from baseline sputum specimens had a PPV and NPV of $15 \%$ (CI; 2-45) and 100\% (CI; 98-100). Real time PCR identification of one $M$. kansasii sputum specimen could not be evaluated since liquid culture and genotype CM failed to identify it.

\section{Cost and time to detection}

The sample unit cost for Mycobacterium real time PCR assay was 12.2 US dollars as compared to 20 US dollars used for liquid culture (see Table 4). The prices quoted don't include the cost of instruments; Roche LightCycler ${ }^{\circ}$ 480 II (18,000\$), BACTEC MGIT 960 (38,950\$) and HAIN twincubator $(3,335 \$)$.

6 hours; 4 minutes was the entire time to run 241 clinical specimens using Real time PCR assay in 6 runs giving an average time to detection for each run 1 hour; 40 minutes for identification of MTB, M. avium, $M$. kansasii or negative. The time to detection for negative liquid culture was 42 days ( 6 weeks) while that of positive cultures was 8 days (IQR 5.3-12.5).

Table 1 Analysis of the sputum specimens by Mycobacterium detection assay and liquid culture

\begin{tabular}{|c|c|c|c|c|c|c|c|c|c|c|}
\hline \multirow{3}{*}{$\begin{array}{l}\text { Type of } \\
\text { sample }\end{array}$} & \multirow{2}{*}{\multicolumn{5}{|c|}{ Mycobacterium detection assay }} & \multicolumn{5}{|c|}{ Liquid culture } \\
\hline & & & & & & \multirow{2}{*}{$\begin{array}{l}\text { Capilia } \\
\text { MTB }\end{array}$} & \multicolumn{2}{|l|}{ HAIN } & \multicolumn{2}{|l|}{ MGIT } \\
\hline & MTB & M. avium & M. kansasii & RT PCR Negative & Total & & M. avium & Other MOTTs & No growth & Total \\
\hline Baseline & 95 & 13 & 1 & 132 & 241 & 94 & 2 & 14 & 131 & 241 \\
\hline
\end{tabular}


Table $22 \times 2$ performance analysis of Real time PCR and Liquid culture

\begin{tabular}{|c|c|c|c|c|c|c|c|}
\hline & & & \multicolumn{5}{|c|}{ Mycobacterium detection assay } \\
\hline & & & MTB & M. avium & M. kansasii & Negative & Total \\
\hline \multirow[t]{3}{*}{ Liquid culture } & Baseline & MTB & 94 & - & - & & 94 \\
\hline & & M. avium & - & 2 & - & - & 2 \\
\hline & & Negative & 1 & 11 & 1 & 132 & 145 \\
\hline
\end{tabular}

\section{Discussion}

Global TB control efforts are based on rapid diagnosis of disease cases followed by adequate treatment thus prevent continued transmission. With increased incidence of TB and non tuberculous disease infection especially among HIV patients, diagnostics with better sensitivity and ability to identify $M$. tuberculosis and non tuberculous mycobacteria are required for appropriate management. Among the commonest non tuberculous mycobacteria affecting HIV patients include $M$. avium and M. kansasii which can be genomic DNA amplified and specific products identified within the same reaction using florescence monitoring by Real time PCR. The recently WHO endorsed Real time PCR based assay; GeneXpert $^{\oplus}$ (Cepheid, Sunnyvale, USA) that offers rapid identification of $\mathrm{MTB}$ and rifampicin resistance but cannot identify $M$. avium and M. kansasii. This study aimed at assessing Mycobacterium real time PCR assay to identify $M$. tuberculosis, $M$. kansasii and $M$. avium from patient clinical specimens at baseline diagnosis and the data shows that Real time PCR was sensitive in identifying MTB at baseline diagnosis and had a significantly short turnaround time compared to liquid culture.

By comparing Real time PCR with liquid culture as the reference standard, its accuracy in identifying mycobacterial species from sputum samples has been demonstrated in this study. Our study showed a high sensitivity

Table 3 Performance of Real time PCR while using Liquid culture as the reference standard

\begin{tabular}{|c|c|c|c|c|}
\hline & \multicolumn{4}{|l|}{ Baseline } \\
\hline & \multicolumn{2}{|l|}{ MTB } & \multicolumn{2}{|l|}{ M. avium } \\
\hline & Estimate & $95 \% \mathrm{Cl}$ & Estimate & $95 \% \mathrm{Cl}$ \\
\hline Sensitivity (\%) & 100 & $96-100$ & 100 & 19-100 \\
\hline Specificity (\%) & 99 & $96-99$ & 95 & $91-97$ \\
\hline Prevalence (\%) & 39 & $33-45$ & 0.8 & $0.1-2.9$ \\
\hline PPV (\%) & 98 & $94-99$ & 15 & $2-45$ \\
\hline NPV (\%) & 100 & $97-100$ & 100 & $98-100$ \\
\hline Likelihood (+) & 144 & 20-1018 & 21 & $12-38$ \\
\hline Likelihood (-) & 0.00 & - & 0.00 & - \\
\hline Kappa stat & 0.9 & $0.9-1.0$ & 0.3 & $-0.03-0.5$ \\
\hline
\end{tabular}

(100\%), specificity (99\%) and positive predictive value (98\%) for identification of MTB from baseline sputum specimens. Previous studies have described the use of Real time PCR in the analysis of sputum samples at baseline diagnosis and reported up 100\% specificity for identification of MTB $[15,16]$. Therefore this Real time PCR assay is a suitable methodology for a clinician to take a decision when identifying MTB from baseline samples. This suggestion is further supported by the excellent agreement between Real time PCR and liquid culture for identification of MTB (kappa statistics, 0.9). However, Real time PCR assay may not be considered as a replacement for culture of MTB given the observation that it identified 1 specimen as MTB positive yet culture indicated it as negative. Clinical decision in the context of the patient may be important especially in the initiation of anti-tuberculosis therapy. Nevertheless, the possibility that missed identification of the specimen can be influenced by other factors such as DNA quality, DNA concentration, extraction method, salt on buffer solution among other factors that could affect amplification [17] cannot be ruled out. These were however not evaluated in this study.

Though this assay had high sensitivity and specificity for identification of $M$. avium from the specimens, it had a low positive predictive value (15\%). This difference is brought about by the discrepancies in the ability of Real time PCR to identify certain species than HAIN genotype Mycobacterium CM; for instance Real time PCR identified $15 \mathrm{M}$. avium, of which only 2 were identified as $M$. avium by liquid culture while using HAIN genotype Mycobacterium CM reverse hybridization assay. This is further supported by the theory of $M$. avium cells being non-viable in liquid culture yet their DNA was identified by Real time PCR assay. Furthermore, one species of M. kansasii was identified by Real time PCR but could not be classified as a mycobacterium species by HAIN genotype Mycobacterium CM following liquid culture. Though another study with a larger sample size is needed to study this discrepancy, a study in South Africa reported M. scrofulaceum (human lymph node isolate) and $M$. flavescens to give a false positive signal for $M$. avium and $M$. kansasii respectively due to the similarity in the hyper variable region $\mathrm{A}$ of 16S RNA [13]. 
Table 4 Costs comparison between Real time PCR assay and liquid culture

\begin{tabular}{|c|c|c|c|c|}
\hline \multirow[t]{2}{*}{ Items } & \multicolumn{2}{|l|}{ Liquid culture } & \multicolumn{2}{|c|}{ Mycobacterium detection assay } \\
\hline & Quantity (Box) & US cost (\$) & Quantity & US cost $(\$)$ \\
\hline Bactec 960 MGIT culture media & 3 & 1,458 & & \\
\hline Bactec 960 MGIT supplement & 2 & 232 & & \\
\hline ZN carbolfuschin stain (BD) & 1 & 79 & & \\
\hline ZN Decolorizer stain (BD) & 1 & 60 & & \\
\hline Methylene Blue stain (BD) & 1 & 70 & & \\
\hline Capilia TB Neo & 1 & 1,200 & & \\
\hline Genotype mycobacterium CM kit & 1 & 1,800 & & \\
\hline Light cycler Mycobacterium detection kit & & & 1 & 2,500 \\
\hline PCR plates & & & 3 & 450 \\
\hline Total & & 4,829 & & 2,950 \\
\hline US Unit cost (\$) (241 samples) & 20.0 & & 12.2 & \\
\hline
\end{tabular}

Mycobacterium real time PCR assay had an average time to detection (1 hour; 40 minutes) significantly lower than that of liquid culture which is comparable to other Real time technology like GeneXpert (2 hours) [18] This greatly reduces the time to initiation of antituberculosis therapy and lost to follow-up cases due to delays in making diagnosis [19]. In this study it was estimated that the unit specimen cost to test using reference standard was almost twice more expensive than use of Real time PCR assay, although the capital costs to buy the respective equipment was not included. In a South African nationwide feasibility study done by Boehme et al. [20] indicated that Real time PCR assays may be more expensive than smear microscopy but the costs were similar to sputum culture. A larger study may be needed to assess the cost effectiveness of this assay compared to liquid culture. Since this assay has amplification and detection done by the Roche 480 II instrument, there are limited chances of assay contamination than other assays like DNA line probe assays that involve further manipulations after amplification. With the demonstrated advantages of using this technique such as capacity to identify the M. tuberculosis and M. avium, high through put ability, cheaper cost than liquid culture and short turnaround time puts this Real time PCR assay at the forefront of molecular techniques to guide TB management especially in highly endemic mycobacterial diseased countries like Uganda.

\section{Conclusion}

The Mycobacterium Real time PCR assay correctly identified the majority of the culture confirmed M. tuberculosis with high specificity though identification of $M$. avium and $M$. kansasii needs to be assessed further especially in high risk population. The utility of this assay for TB diagnosis was comparable with liquid culture; thus it can be adopted in a clinical setting. This assay proved to be a rapid and cost-effective test compared to liquid culture for identification of $M$. tuberculosis and M. avium from clinical specimens.

\section{Competing interests}

The authors declare that they have no competing interests.

\section{Authors' contributions}

Conceived and designed the experiments: BA, WE, ME, OS, MJ. Performed the experiments: BA, MC, AK. Analyzed the data: BA, WE, MP. Data interpretation: $B A, W E, M C, M P, A K, H S, O S, M E, M J$. Critical revision of manuscript: $B A, W E, M C, M P, H S, A K, O S, M E, M J$. All authors read and approved the final manuscript.

\section{Acknowledgement}

This study was financially supported by the Forgarty International Centre (FIC)/National Insitutes of Health (NIH) grant number 2 U2R TW0006879 through the International Clinical Operational and Health Services Research (COHRE) at Joint Clinical Research Centre under; a collaborative training program implemented with Makerere University, Mbarara University of Science and Technology, Kampala City Council Authority, Case Western University and University of Georgia. Special thanks to the staff of Joint Clinical Research Centre-Mycobacteriology laboratory for their guidance and support.

\section{Author details}

${ }^{1}$ Department of Medical Microbiology, College of Health sciences, Makerere University, Kampala, Uganda. ${ }^{2} J o i n t$ Clinical Research Centre, P.O. Box 10005, Kampala, Lubowa, Uganda. ${ }^{3}$ Uganda-CASE Research Collaboration, Kampala, Uganda. ${ }^{4}$ Department of Bio molecular Resources and Bio laboratory Sciences, College of Veterinary Medicine, Animal resource and Bio-security, Kampala, Uganda.

Received: 27 December 2014 Accepted: 1 April 2015 Published online: 14 April 2015

\section{References}

1. Tobin MJ. Tuberculosis, lung infections, and interstitial lung disease in AJRCCM 2000. Am J Respir Crit Care Med. 2001;164(10 Pt 1):1774-88.

2. WHO: Global Tuberculosis Report. In. Edited by Data WLC-i-P: World Health Organisation; 2014: 1-134. 
3. Corbett EL, Marston B, Churchyard GJ, De Cock KM. Tuberculosis in sub-Saharan Africa: opportunities, challenges, and change in the era of antiretroviral treatment. Lancet. 2006;367(9514):926-37.

4. Gopinath K and Singh S. Non-tuberculous mycobacteria in TB-endemic countries: are we neglecting the danger? PLos Neglected Tropical Diseases. 2010; 4 (4).

5. Johnson MM, Waller EA, Leventhal JP. Nontuberculous mycobacterial pulmonary disease. Curr Opin Pulm Med. 2008;14(3):203-10.

6. Lawn SD. Pre-screening with GeneXpert (R) MTB/RIF may increase use of isoniazid preventive therapy in antiretroviral programmes. Int J Tuberc Lung Dis. 2011;15(9):1272-3. author reply 1273-1274.

7. World Health Organization. Laboratory services in TB control, part I: organization and management, In., vol. 1. Geneva: WHO; 1998

8. Pai M, Minion J, Sohn H, Zwerling A, Perkins MD. Novel and improved technologies for tuberculosis diagnosis: progress and challenges. Clin Chest Med. 2009;30(4):701-16. viii.

9. Albert $H$, Bwanga F, Mukkada S, Nyesiga B, Ademun JP, Lukyamuzi G, et al. Rapid screening of MDR-TB using molecular line probe assay is feasible in Uganda. BMC Infect Dis. 2010;10:41.

10. Teo J, Jureen R, Chiang D, Chan D, Lin R. Comparison of two nucleic acid amplification assays, the Xpert MTB/RIF assay and the amplified Mycobacterium tuberculosis direct assay, for detection of Mycobacterium tuberculosis in respiratory and nonrespiratory specimens. J Clin Microbiol. 2011;49(10):3659-62.

11. World Health Organization. Automated real-time nucleic acid amplification technology for rapid and simultaneous detection of tuberculosis and rifampicin resistance: Xpert MTB/RIF system. Geneva, Switzerland: World Health Organization; 2011.

12. Light cycler mycobacterium detection kit, version April 2009; Roche Diagnostics Gmbh, Mannheim, Germany.

13. Omar SV, Roth A, Ismail NA, Erasmus L, Ehlers M, Kock M, et al. Analytical performance of the Roche LightCycler (R) Mycobacterium detection kit for the diagnosis of clinically important mycobacterial species. PLoS One. 2011;6(9):e24789.

14. Kubica GP. Phage typing of Mycobacterium tuberculosis: a time for standardization. Am Rev Respir Dis. 1982;126(1):3-4.

15. Richardson ET, Samson D, Banaei N. Rapid Identification of Mycobacterium tuberculosis and nontuberculous mycobacteria by multiplex, real-time PCR. J Clin Microbiol. 2009;47(5):1497-502.

16. Nasr Esfahani B, Rezaei Yazdi H, Moghim S, Ghasemian Safaei H, Zarkesh Esfahani $\mathrm{H}$. Rapid and accurate identification of Mycobacterium tuberculosis complex and common non-tuberculous mycobacteria by multiplex real-time PCR targeting different housekeeping genes. Curr Microbiol. 2012;65(5):493-9.

17. Perng CL, Chen HY, Chiueh TS, Wang WY, Huang CT, Sun JR. Identification of non-tuberculous mycobacteria by real-time PCR coupled with a high-resolution melting system. J Med Microbiol. 2012;61(Pt 7):944-51.

18. Sekadde MP, Wobudeya E, Joloba ML, Ssengooba W, Kisembo H, Bakeera-Kitaka S, et al. Evaluation of the Xpert MTB/RIF test for the diagnosis of childhood pulmonary tuberculosis in Uganda: a cross-sectional diagnostic study. BMC Infect Dis. 2013;13:133.

19. Ortu S, Molicotti P, Sechi LA, Pirina P, Saba F, Vertuccio C, et al. Rapid detection and identification of Mycobacterium tuberculosis by real time PCR and bactec 960 MIGT. New Microbiol. 2006;29(1):75-80

20. Boehme CC, Nicol MP, Nabeta P, Michael JS, Gotuzzo E, Tahirli R, et al. Feasibility, diagnostic accuracy, and effectiveness of decentralised use of the Xpert MTB/RIF test for diagnosis of tuberculosis and multidrug resistance: a multicentre implementation study. Lancet. 2011;377(9776):1495-505.

\section{Submit your next manuscript to BioMed Central and take full advantage of:}

- Convenient online submission

- Thorough peer review

- No space constraints or color figure charges

- Immediate publication on acceptance

- Inclusion in PubMed, CAS, Scopus and Google Scholar

- Research which is freely available for redistribution

Submit your manuscript at www.biomedcentral.com/submit 